\title{
MODELLING CHLORIDE DIFFUSION IN CONCRETE WITH INFLUENCE OF CONCRETE STRESS STATE
}

\author{
Jian WANG ${ }^{\text {a }}$, Pui-Lam NG ${ }^{\text {b }}$, Weishan $W_{A N G}{ }^{c}$, Jinsheng DU ${ }^{\mathrm{a}}$, Jianyong SONG \\ ${ }^{a}$ School of Civil Engineering, Beijing Jiaotong University, Beijing, China \\ ${ }^{b}$ Faculty of Civil Engineering, Vilnius Gediminas Technical University, Vilnius, Lithuania \\ ${ }^{c}$ Highway Research Institute of Xi'an, Xi'an, China \\ ${ }^{d}$ Research Institute of Highway Ministry of Transport, Beijing, China
}

Received 16 Apr 2017; accepted 05 Jun 2017

\begin{abstract}
Under coastal or marine conditions, chloride erosion is the major accelerating factor of reinforcement corrosion. Therefore, it is of vital importance to investigate the chloride diffusion model. Research reveals that the concrete stress state has great influence on chloride diffusion; therefore a stress influence coefficient was incorporated in chloride diffusion coefficient model by many researchers. By referring to the experimental data from eight different researchers, the law between stress influence coefficient and concrete stress ratio is studied in detail, and equations relating the stress influence coefficient with the concrete stress ratio are established. Compared with three typical existing groups of equations, it is found that the proposed equations give the most accurate estimation of the stress influence coefficient. Hence, the proposed equations can be adopted to improve the valuation of chloride diffusion coefficient, and a modified chloride diffusion model is put forward. Three groups of experimental data are used to validate the modified chloride diffusion model, which is shown to be reasonable and having high prediction accuracy.
\end{abstract}

Keywords: chloride diffusion, concrete stress state, reinforcement corrosion, stress influence coefficient.

\section{Introduction}

Under the aggressive conditions of coastal or marine environment, chloride erosion is the main accelerating factor to aggravate the corrosion of steel reinforcement (Wang et al. 2014; Álava et al. 2016). Due to the fact that reinforcement corrosion is one of the most critical problems that impair the durability of concrete structures (Zhou et al. 2015; Zhang, Zhao 2016), it is important to study the behaviour of chloride migration so that more appropriate mitigation measures could be devised. Because the chloride ion penetrates into the internal part of concrete mainly in the manner of diffusion, the chloride diffusion model has been investigated by many researchers (e.g. Zhang, Gjørv 1996; Zhou 2014, 2016).

It is noted that most of the studies on chloride diffusion pertain to reinforced concrete in an unstressed state. Concrete structures in service, however, are generally in a stressed state. Previous research had indicated that the chloride ion penetration process in concrete in the stressed state differs from that of unstressed concrete (e.g. He 2004; Li et al. 2011, 2014). He (2004), Wang et al. (2011), Li et al. (2011) and Fu et al. (2016) confirmed that the chloride ions penetrated more quickly into concrete under tensile stress state than concrete under zero-stress state, and the rate of chloride ion penetration was slowest in concrete under compressive stress state. A possible explanation for these phenomena would be the compressive stress may reduce the porosity of concrete by closing some microcracks or capillaries that exist in the direction of diffusion. On the contrary, tensile stress can damage the aggregate-paste interface which causes increase in the porosity of concrete (Jin et al. 2015; Xu, Li 2017).

In order to consider the influence of concrete stress state on chloride diffusion, some researchers incorporated a stress influence coefficient in the chloride diffusion coefficient model (e.g. Wang et al. 2011, 2014, 2016), and the stress influence coefficient $d$ was expressed as a function of concrete stress ratio $\sigma_{c(t)} / f_{c(t)}\left(\sigma_{c(t)}\right.$ denotes the concrete stress and $f_{c(t)}$ denotes the concrete compressive or tensile strength dependent on whether $\sigma_{c(t)}$ is compressive or tensile). However, because of the limited and discrete experimental data, only a few research works had addressed the influence of concrete stress state on chloride diffusion satisfactorily.

Huang (2007), Zhang (2001) and Li et al. (2011) studied the relationship between stress influence co-

Corresponding author: Pui-Lam Ng

E-mail: irdngpl@gmail.com 
efficient and concrete stress $\sigma_{c(t)}$ experimentally and performed curve fitting of the experimental data. Considering the fact that different grades of concrete have different tensile and compressive strengths, the same stress in concrete might equate to different proportions of tensile and compressive strengths of concrete of different grades. Therefore, for different grades of concrete, the influences of the same stress on chloride diffusion would be different. As a result, the laws relating the stress influence coefficient with the concrete stress are dependent on the concrete grade. With the aim to devise the stress influence coefficient equations suitable for different concrete grades, the authors collect experimental data in the literature (Zhang 2001; Shui 2005; Huang 2007; Kim et al. 2010; Li et al. 2011, 2014; Sun et al. 2011; Jin et al. 2011) to further investigate the relationship between stress influence coefficient and concrete stress ratio, the relevant equations are proposed and a modified chloride diffusion model is obtained in this paper. At last, three groups of experimental data are used to validate the modified chloride diffusion model.

\section{Chloride diffusion model}

The Fick's second law of diffusion is commonly applied to quantify the chloride penetration under coastal or marine conditions (Costa, Appleton 1999; Ababneh et al. 2003), and it is given by the following expression:

$$
\frac{\partial C}{\partial t}=D \frac{\partial^{2} C}{\partial x^{2}}
$$

where $C$-chloride concentration in concrete at depth $x$ and exposure time $t ; D$-chloride diffusion coefficient.

The mathematical solution to Eqn (1) for a semiinfinite concrete with a constant surface concentration $C_{s}$, chloride diffusion coefficient $D$, an initial chloride concentration $C_{0}$, and the depth of convection zone $\Delta x$ was provided by Fib Bulletin 34 (2006), as shown in Eqn (2) (Meira et al. 2010; Zhou 2014):

$$
C_{x, t}=C_{0}+\left(C_{s}-C_{0}\right)\left[1-\operatorname{erf}\left(\frac{x-\Delta x}{2 \sqrt{D t}}\right)\right],
$$

where $C_{x, t}-$ total content of chlorides at depth $x$ and exposure time $t, \% ; C_{0}$ - initial chloride concentration in concrete, $\% ; C_{S}$ - surface chloride concentration, $\% ; \Delta x-$ convection zone depth, $\mathrm{m}$; and erf is the error function.

The surface chloride concentration $C_{S}$ is not constant in many cases but has a surface chloride building-up process, which has been observed mostly in two patterns. The first one is a linear pattern of surface chloride buildup (Mustafa, Yusof 1994; Costa, Appleton 1999; Meira et al. 2010; Zhou 2014), especially for the concrete exposed to airborne chloride, deicing salt and spray conditions. The second one is a square root build-up (Shin,
Kim 2002; Kato et al. 2005), especially for the wet and dry cycles condition.

For the linear pattern of surface chloride build-up, the relationship between $C_{S}$ and exposure time $t$ can be expressed as (Zhou 2014):

$$
C_{s}-C_{0}=k t,
$$

where $k$ - constant for increased rate of surface chloride content, $\% / \mathrm{s}$. The length of this surface chloride build-up period depends on the exposure environments. A longer period is expected for airborne chloride and deicing salt conditions and a shorter time for tidal, spray, splashing, and other related conditions.

Equation (2) is only suitable for a constant diffusivity. The chloride diffusion coefficient has been found to decrease with time for at least a period of time from the beginning of exposure due to the continuous cement hydration and the consequent densification of microstructure of concrete (Stanish, Thomas 2003; Tang, Gulikers 2007), and the diffusivity-decreasing process is expected to stop when the cement hydration completes after a certain period. The length of such period given by Ehlen et al. (2009), Life-365 (2012) and Ehlen and Kojundic (2014) is 25 years. The relationship between chloride diffusion coefficient and time can be expressed by Eqn (4):

$$
D_{a}=D_{r}\left(\frac{t_{a}}{t_{r}}\right)^{-m}
$$

where $D_{a}$ - chloride diffusion coefficient at the age of $t_{a} ; D_{r}$ - reference chloride diffusion coefficient tested at the age of $t_{r} ; m$ - age factor, which can be obtained from Ehlen et al. (2009), Life-365 (2012) and Ehlen and Kojundic (2014).

When the chloride diffusion coefficient is constant, initial chloride concentration is zero and consider a linear pattern of surface chloride build-up, the chloride diffusion can be described using Eqn (5) (Crank 1975). This equation was also recommended by ACI Committee 365 (2000):

$$
C_{x, t}=k t\left[\left(1+\frac{x^{2}}{2 D t}\right) \operatorname{erfc}\left(\frac{x}{2 \sqrt{D t}}\right)-\frac{x}{\sqrt{\pi D t}} \exp \left(\frac{-x^{2}}{4 D t}\right)\right]
$$

in which erfc is the complement error function.

To consider an initial chloride concentration $C_{0}$, a convection zone depth $\Delta x$ and a decreasing chloride diffusion coefficient, Eqn (5) can be rewritten to Eqn (6). This process is also called the first period of chloride diffusion, and the length of this period is around 10 years for marine splashing zone, and 15 years or longer for atmosphere in coastal area (Ehlen et al. 2009; Ehlen, Kojundic 2014; Zhou 2014). 
$C_{x, t e}=C_{0}+k t_{e}$

$\left\{\left[1+\frac{(x-\Delta x)^{2}(1-m)}{2 D_{r} t_{r}^{m}\left(\left[t_{e}+t_{a 0}\right]^{1-m}-t_{a 0}^{t-m}\right)}\right] \operatorname{erfc}\left[\frac{(x-\Delta x) \sqrt{1-m}}{2 \sqrt{D_{r} t_{r}^{m}\left(\left[t_{e}+t_{a 0}\right]^{1-m}-t_{a 0}^{1-m}\right)}}\right]-\frac{(x-\Delta x) \sqrt{1-m}}{\sqrt{\pi D_{r} t_{r}^{m}\left(\left[t_{e}+t_{a 0}\right]^{1-m}-t_{a 0}^{1-m}\right)}} \exp \left[\frac{-(x-\Delta x)^{2}(1-m)}{4 D_{r} t_{r}^{m}\left(\left[t_{e}+t_{a 0}\right]^{1-m}-t_{a 0}^{1-m}\right)}\right]\right\}$,

where $C_{x, t e}-$ total content of chlorides at depth $x$ and exposure time $t_{e}, \% ; t_{e}$ - duration of exposure time, s; $t_{a 0}$ - age of concrete at the start of exposure, s. The subsequent two exposure periods proposed by Zhou (2014) with a constant surface chloride concentration together with either a decreasing chloride diffusion coefficient or a constant one are not discussed in this paper.

\section{Establishing equations for stress influence coefficient}

Although the ingress of chloride into concrete is primarily dominated by diffusion, the concrete stress state can affect this process by modifying the microstructure of concrete. Concrete structures may be subjected to various loading conditions under service conditions. Therefore, to predict the chloride ingress into real structures under service conditions, the effects of different concrete stress states on the chloride transport should be considered.

To account for the influence of concrete stress state on chloride diffusion, a stress influence coefficient can be incorporated in Eqn (4), as expressed in Eqn (7):

$$
D_{\sigma}=K_{k s} D_{a}=K_{k s} D_{r}\left(\frac{t_{a}}{t_{r}}\right)^{-m},
$$

where $D_{\sigma}$ - chloride diffusion coefficient under concrete stress state at the age of $t_{a}, \mathrm{~m}^{2} / \mathrm{s} ; D_{a}$ - chloride diffusion coefficient under zero-stress state at the age of $t_{a}, \mathrm{~m}^{2} / \mathrm{s}$; $D_{r}$ - reference chloride diffusion coefficient of concrete at the age of test or measurement $t_{r}$ under zero-stress state, $\mathrm{m}^{2} / \mathrm{s} ; K_{k s}-$ stress influence coefficient, which indicates the influence of concrete stress state on chloride diffusion. Eqn (7) can also be written as:

$$
K_{k s}=\frac{D_{\sigma}}{D_{a}} .
$$

With respect to Eqn (8), the equations of stress influence coefficient can be obtained if the chloride diffusion coefficients at given concrete stress state and zero-stress state are known. To conduct numerical analysis, it is assumed that $K_{k s}$ has no coupling with other factors such as

Table 1. Chloride diffusion coefficient under different concrete stress states (data from Jin et al. 2011)

\begin{tabular}{c|c|c|c|c|c|c|c|c|c}
\hline Specimen & $f_{t}(\mathrm{MPa})$ & $\delta_{T}$ & $D\left(10^{-6} \mathrm{~mm}^{2} / \mathrm{s}\right)$ & $K_{k s}$ & Specimen & $f_{c}(\mathrm{MPa})$ & $\delta_{C}$ & $D\left(10^{-6} \mathrm{~mm}^{2} / \mathrm{s}\right)$ & $K_{k s}$ \\
\hline C40 & 2.58 & 0 & 3.25 & 1 & C40 & 28.5 & 0 & 11.10 & 1 \\
B41 & 2.58 & 0.223 & 3.90 & 1.200 & A41 & 28.5 & 0.220 & 10.80 & 0.973 \\
B42 & 2.58 & 0.402 & 3.75 & 1.154 & A42 & 28.5 & 0.367 & 10.15 & 0.914 \\
B43 & 2.58 & 0.500 & 4.15 & 1.277 & A43 & 28.5 & 0.514 & 9.85 & 0.887 \\
C50 & 2.14 & 0 & 5.73 & 1 & C50 & 21.7 & 0 & 12.85 & 1 \\
B51 & 2.14 & 0.312 & 6.25 & 1.091 & A51 & 21.7 & 0.221 & 12.30 & 0.957 \\
B52 & 2.14 & 0.474 & 6.50 & 1.134 & A52 & 21.7 & 0.368 & 11.65 & 0.907 \\
B53 & 2.14 & 0.603 & 6.68 & 1.166 & A53 & 21.7 & 0.515 & 11.09 & 0.863 \\
\hline
\end{tabular}

Table 2. Chloride diffusion coefficient under different concrete stress states (data from Zhang 2001)

\begin{tabular}{c|c|c|c|c|c|c|c|c|c}
\hline Specimen & $f_{t}(\mathrm{MPa})$ & $\delta_{T}$ & $D\left(10^{-6} \mathrm{~mm}^{2} / \mathrm{s}\right)$ & $K_{k s}$ & Specimen & $f_{c}(\mathrm{MPa})$ & $\delta_{C}$ & $D\left(10^{-6} \mathrm{~mm}^{2} / \mathrm{s}\right)$ & $K_{k s}$ \\
\hline 1 & 1.84 & 0 & 3.850 & 1 & 1 & 20.3 & 0 & 9.169 & 1 \\
2 & 1.84 & 0.3 & 3.855 & 1.001 & 2 & 20.3 & 0.3 & 8.959 & 0.977 \\
3 & 1.84 & 0.5 & 4.103 & 1.066 & 3 & 20.3 & 0.5 & 7.694 & 0.839 \\
4 & 1.84 & 0.7 & 4.116 & 1.069 & 4 & 20.3 & 0.7 & 6.690 & 0.730 \\
5 & 1.53 & 0 & 6.125 & 1 & 5 & 15.5 & 0 & 9.639 & 1 \\
6 & 1.53 & 0.3 & 6.327 & 1.033 & 6 & 15.5 & 0.3 & 9.570 & 0.993 \\
7 & 1.53 & 0.5 & 6.560 & 1.071 & 7 & 15.5 & 0.5 & 9.265 & 0.961 \\
8 & 1.53 & 0.7 & 6.633 & 1.083 & 8 & 15.5 & 0.7 & 8.553 & 0.887 \\
\hline
\end{tabular}


Table 3. Chloride diffusion coefficient under different concrete stress states (data from Huang 2007)

\begin{tabular}{c|c|c|c|c|c|c|c|c|c}
\hline Specimen & $f_{t}(\mathrm{MPa})$ & $\delta_{T}$ & $D\left(10^{-6} \mathrm{~mm}^{2} / \mathrm{s}\right)$ & $K_{k s}$ & Specimen & $f_{c}(\mathrm{MPa})$ & $\delta_{C}$ & $D\left(10^{-6} \mathrm{~mm}^{2} / \mathrm{s}\right)$ & $K_{k s}$ \\
\hline $\mathrm{W}-1$ & 2.65 & 0 & 48.9 & 1 & $\mathrm{~W}-1$ & 33.6 & 0 & 48.9 & 1 \\
$\mathrm{~T}-1$ & 2.65 & 0.22 & 51.8 & 1.059 & $\mathrm{C}-1$ & 33.6 & 0.05 & 46.0 & 0.941 \\
$\mathrm{~T}-2$ & 2.65 & 0.44 & 56.6 & 1.157 & $\mathrm{C}-2$ & 33.6 & 0.09 & 40.6 & 0.830 \\
$\mathrm{~T}-3$ & 2.65 & 0.66 & 61.2 & 1.252 & $\mathrm{C}-3$ & 33.6 & 0.14 & 35.6 & 0.728 \\
$\mathrm{~T}-4$ & 2.65 & 0.88 & 76.3 & 1.560 & $\mathrm{C}-4$ & 33.6 & 0.18 & 26.1 & 0.534 \\
$\mathrm{~W}-1$ & 2.42 & 0 & 52.0 & 1 & $\mathrm{~W}-1$ & 27.3 & 0 & 52.0 & 1 \\
$\mathrm{~T}-5$ & 2.42 & 0.22 & 55.3 & 1.063 & $\mathrm{C}-5$ & 27.3 & 0.06 & 49.8 & 0.958 \\
$\mathrm{~T}-6$ & 2.42 & 0.44 & 60.3 & 1.160 & $\mathrm{C}-6$ & 27.3 & 0.11 & 44.9 & 0.863 \\
$\mathrm{~T}-7$ & 2.42 & 0.66 & 67.0 & 1.288 & $\mathrm{C}-7$ & 27.3 & 0.17 & 39.0 & 0.750 \\
$\mathrm{~T}-8$ & 2.42 & 0.88 & 80.5 & 1.548 & $\mathrm{C}-8$ & 27.3 & 0.22 & 29.0 & 0.558 \\
\hline
\end{tabular}

Table 4. Chloride diffusion coefficient under different concrete stress states (data from Li et al. 2011)

\begin{tabular}{l|c|c|c|c|l|c|c|c|c}
\hline \multicolumn{1}{c|}{ Specimen } & $f_{t}(\mathrm{MPa})$ & $\delta_{T}$ & $D\left(10^{-6} \mathrm{~mm}^{2} / \mathrm{s}\right)$ & $K_{k s}$ & Specimen & $f_{c}(\mathrm{MPa})$ & $\delta_{C}$ & $D\left(10^{-6} \mathrm{~mm}^{2} / \mathrm{s}\right)$ & $K_{k s}$ \\
\hline SSI-N-D40 & 2.80 & 0 & 0.667 & 1 & SSI-N-D40 & 31.4 & 0 & 0.667 & 1 \\
SSI-TK30-D40 & 2.80 & 0.3 & 0.797 & 1.195 & SSI-CK30-D40 & 31.4 & 0.3 & 0.510 & 0.765 \\
SSI-TK50-D40 & 2.80 & 0.5 & 0.830 & 1.245 & SSI-CK50-D40 & 31.4 & 0.5 & 0.604 & 0.905 \\
SSI-N-D60 & 2.80 & 0 & 0.479 & 1 & SSI-N-D60 & 31.4 & 0 & 0.479 & 1 \\
SSI-TK30-D60 & 2.80 & 0.3 & 0.573 & 1.198 & SSI-CK30-D60 & 31.4 & 0.3 & 0.363 & 0.759 \\
SSI-TK50-D60 & 2.80 & 0.5 & 0.594 & 1.241 & SSI-CK50-D60 & 31.4 & 0.5 & 0.426 & 0.891 \\
SSI-N-D90 & 2.80 & 0 & 0.341 & 1 & SSI-N-D90 & 31.4 & 0 & 0.341 & 1 \\
SSI-TK30-D90 & 2.80 & 0.3 & 0.396 & 1.161 & SSI-CK30-D90 & 31.4 & 0.3 & 0.251 & 0.737 \\
SSI-TK50-D90 & 2.80 & 0.5 & 0.425 & 1.246 & SSI-CK50-D90 & 31.4 & 0.5 & 0.279 & 0.818 \\
\hline
\end{tabular}

Table 5. Chloride diffusion coefficient under different concrete stress states (data from Li et al. 2014)

\begin{tabular}{c|c|c|c|c|c|c|c|c|c}
\hline Specimen & $f_{t}(\mathrm{MPa})$ & $\delta_{T}$ & $D\left(10^{-6} \mathrm{~mm}^{2} / \mathrm{s}\right)$ & $K_{k s}$ & Specimen & $f_{c}(\mathrm{MPa})$ & $\delta_{C}$ & $D\left(10^{-6} \mathrm{~mm}^{2} / \mathrm{s}\right)$ & $K_{k s}$ \\
\hline $\mathrm{T} 1-0$ & 2.30 & 0 & 3.9 & 1 & $\mathrm{C} 1-0$ & 24.22 & 0 & 6.2 & 1 \\
$\mathrm{~T} 1-1$ & 2.30 & 0.174 & 4.2 & 1.077 & $\mathrm{C} 1-1$ & 24.22 & 0.396 & 5.5 & 0.887 \\
$\mathrm{~T} 1-2$ & 2.39 & 0.335 & 4.5 & 1.154 & $\mathrm{C} 1-2$ & 25.46 & 0.754 & 5.0 & 0.806 \\
$\mathrm{~T} 1-3$ & 2.34 & 0.513 & 5.2 & 1.333 & $\mathrm{C} 2-0$ & 33.40 & 0 & 5.5 & 1 \\
$\mathrm{~T} 1-4$ & 2.42 & 0.661 & 6.8 & 1.744 & $\mathrm{C} 2-1$ & 33.40 & 0.198 & 5.2 & 0.945 \\
- & - & - & - & - & $\mathrm{C} 2-2$ & 34.27 & 0.385 & 4.0 & 0.727 \\
- & - & - & - & - & $\mathrm{C} 2-3$ & 34.27 & 0.578 & 3.5 & 0.673 \\
- & - & - & - & - & $\mathrm{C} 2-4$ & 34.48 & 0.789 & 5.0 & 0.962 \\
- & - & - & - & - & $\mathrm{C} 3-0$ & 39.42 & 0 & 3.9 & 1 \\
- & - & - & - & - & $\mathrm{C} 3-1$ & 39.42 & 0.203 & 3.5 & 0.897 \\
- & - & - & - & - & $\mathrm{C} 3-2$ & 40.00 & 0.400 & 2.5 & 0.641 \\
- & - & - & - & - & $\mathrm{C} 3-3$ & 40.00 & 0.600 & 3.4 & 0.872 \\
- & - & - & - & - & $\mathrm{C} 3-4$ & 40.15 & 0.797 & 5.0 & 1.282 \\
\hline
\end{tabular}

time and water/cement ratio of concrete (corresponding assumptions are also contained in vast literature, such as Gowripalan et al. 2000; Wang et al. 2011; Rahman et al. $2012)$. In other words, $K_{k s}$ is only a function of the concrete stress ratio $\delta\left(\delta=\sigma_{c(t)} / f_{c(t)}\right)$.

In the following, reference is made to experimental data in the literature, as summarised in Tables 1 to $8\left(f_{t}\right.$ and $\delta_{T}$ are respectively the concrete tensile strength and tensile stress ratio; and $f_{c}$ and $\delta_{C}$ are respectively the concrete compressive strength and compressive stress ratio).
These data are utilised to study the relationship between stress influence coefficient and concrete stress ratio.

The relationships between $K_{k s}$ and concrete tensile and compressive stress ratios are plotted in Figures 1 and 2 , respectively. It can be seen from the figures that the stress influence coefficient has approximately linear relationship with the concrete tensile stress ratio, while the relationship between the stress influence coefficient and the concrete compressive stress ratio can be approximately described by a quadratic function. The relation- 
Table 6. Chloride diffusion coefficient under different concrete stress states (data from Sun et al. 2011)

\begin{tabular}{c|c|c|c|c|c|c|c|c|c}
\hline Specimen & $f_{c}(\mathrm{MPa})$ & $\delta_{C}$ & $D\left(10^{-6} \mathrm{~mm}^{2} / \mathrm{s}\right)$ & $K_{k s}$ & Specimen & $f_{c}(\mathrm{MPa})$ & $\delta_{C}$ & $D\left(10^{-6} \mathrm{~mm}^{2} / \mathrm{s}\right)$ & $K_{k s}$ \\
\hline \multirow{6}{*}{$\mathrm{C} 3 \mathrm{~F}$} & 34.2 & 0 & 2.67 & 1 & & 42.1 & 0 & 2.09 & 1 \\
& 34.2 & 0.1 & 2.35 & 0.880 & & 42.1 & 0.1 & 1.82 & 0.871 \\
& 34.2 & 0.3 & 2.22 & 0.831 & $\mathrm{C} 4 \mathrm{~F}$ & 42.1 & 0.3 & 1.77 & 0.847 \\
& 34.2 & 0.5 & 2.29 & 0.858 & & 42.1 & 0.5 & 1.85 & 0.885 \\
& 34.2 & 0.7 & 2.41 & 0.903 & & 42.1 & 0.7 & 2.15 & 1.029 \\
\hline
\end{tabular}

Table 7. Chloride diffusion coefficient under different concrete stress states (data from Kim et al. 2010)

\begin{tabular}{c|c|c|c|c|c|c|c|c|c}
\hline Specimen & $f_{t}(\mathrm{MPa})$ & $\delta_{T}$ & $D\left(10^{-6} \mathrm{~mm}^{2} / \mathrm{s}\right)$ & $K_{k s}$ & Specimen & $f_{t}(\mathrm{MPa})$ & $\delta_{T}$ & $D\left(10^{-6} \mathrm{~mm}^{2} / \mathrm{s}\right)$ & $K_{k s}$ \\
\hline \multirow{3}{*}{ BFS8000-50 } & 2.37 & 0 & 5.0 & 1 & & 2.25 & 0 & 4.0 & 1 \\
& 2.37 & 0.3 & 6.0 & 1.20 & BFS6000-70 & 2.25 & 0.3 & 4.5 & 1.125 \\
& 2.37 & 0.6 & 7.5 & 1.50 & & 2.25 & 0.6 & 5.5 & 1.375 \\
\hline
\end{tabular}

Table 8. Chloride diffusion coefficient under different concrete stress states (data from Shui 2005)

\begin{tabular}{c|c|c|c|c|c|c|c|c|c}
\hline Specimen & $f_{t}(\mathrm{MPa})$ & $\delta_{T}$ & $D\left(10^{-6} \mathrm{~mm}^{2} / \mathrm{s}\right)$ & $K_{k s}$ & Specimen & $f_{c}(\mathrm{MPa})$ & $\delta_{C}$ & $D\left(10^{-6} \mathrm{~mm}^{2} / \mathrm{s}\right)$ & $K_{k s}$ \\
\hline C35-CX & 1.57 & 0 & 5.847 & 1 & C35-CX & 16.7 & 0 & 5.474 & 1 \\
C35-CXL3-T & 1.57 & 0.3 & 7.748 & 1.325 & C35-CXL3-C & 16.7 & 0.3 & 3.492 & 0.638 \\
C35-CXL6-T & 1.57 & 0.6 & 9.013 & 1.542 & C35-CXL6-C & 16.7 & 0.6 & 3.888 & 0.710 \\
\hline
\end{tabular}

ship between $K_{k s}$ and concrete tensile and compressive stress ratios can be mathematically established by means of regression analysis, as given by Eqn (9a) (coefficient of correlation $R^{2}=0.992$ ) and Eqn (9b) (coefficient of correlation $R^{2}=0.987$ ) respectively. In Eqn (9a), the value of $\delta_{T}$ is limited to 1.0. Considering that the longterm compressive strength of concrete structures under sustained load is generally taken as $0.80 f_{\mathcal{c}}$, in Eqn (9b), $\delta_{C}$ should not be greater than 0.8 .

Under tension: $\quad K_{k s}=1.0+0.45 \delta_{T} \quad\left(0 \leq \delta_{T} \leq 1.0\right) ;(9 \mathrm{a})$

Under compression: $K_{k s}=1.0-0.88 \delta_{C}+\delta_{C}^{2}$

$$
\left(0 \leq \delta_{C} \leq 0.8\right) \text {. }
$$

Figure 1 shows that $K_{k s}$ increases monotonically with $\delta_{T}$. Figure 2 shows that $K_{k s}$ has a minimum value. The $K_{k s}$ decreases with increasing $\delta_{C}$ when compressive stress ratio is lower than a certain value, and increases with increasing $\delta_{C}$ when compressive stress ratio is higher than that value. This is because transverse deformation and micro-cracks due to compression damage accelerate the penetration of chloride ions. In Eqn (9b), $K_{k s}$ attains the minimum value of 0.81 when $\delta_{C}$ is equal to 0.44 .

\section{Evaluating the proposed equations}

To evaluate the accuracy of the proposed equations, Eqn (9a) and Eqn (9b) are statistically compared with other three typical existing groups of equations (Wang et al. 2011, 2014; Wang 2012) in terms of deviation.
Eqn (10a) and Eqn (10b) were proposed by Wang et al. (2014):

Under tension: $K_{k s}=1+0.3034 \delta_{T}+0.4235 \delta_{T}^{2}$;

Under compression: $K_{k s}=1-2.1255 \delta_{C}+3.0332 \delta_{C}^{2}$.

(10b)

The proposed equations by Wang (2012) are given as:

Under tension: $K_{k s}=1-0.1296 \delta_{T}+0.8291 \delta_{T}^{2}$;

Under compression: $K_{k s}=1-1.2463 \delta_{C}+1.9091 \delta_{C}^{2}$.

Eqn (12a) and Eqn (12b) were obtained by the research of Wang et al. (2011):

Under tension: $\quad K_{k s}=1+0.35 \delta_{T}$;

Under compression: $K_{k s}=1-0.28 \delta_{C}$.

The deviation is the difference between the computed results of stress influence coefficient (denoted by $K_{k s}^{c}$ ) and the experimentally obtained stress influence coefficient (denoted by $K_{k s}^{t}$ ). A smaller absolute value of deviation indicates a higher accuracy of the equations.

As shown in Figure 3, with the increase of the concrete tensile stress ratio, the deviations of Eqn (9a) to 


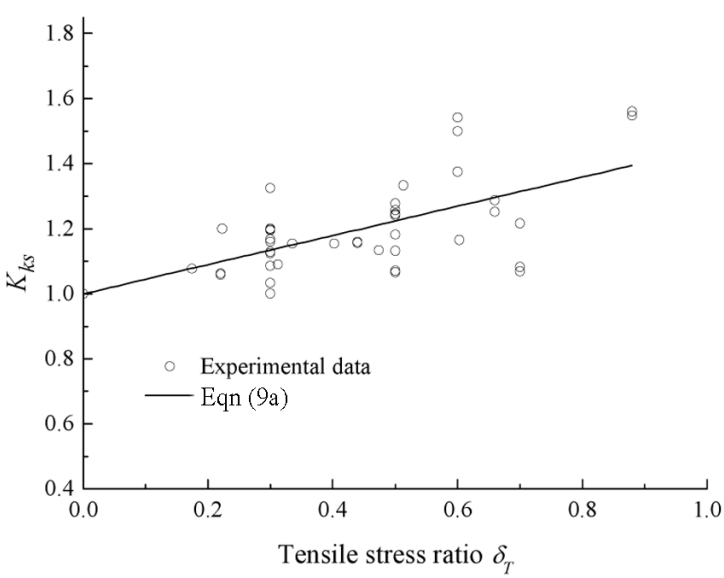

Fig. 1. Relationship between $K_{k s}$ and concrete tensile stress ratio $\delta_{T}$

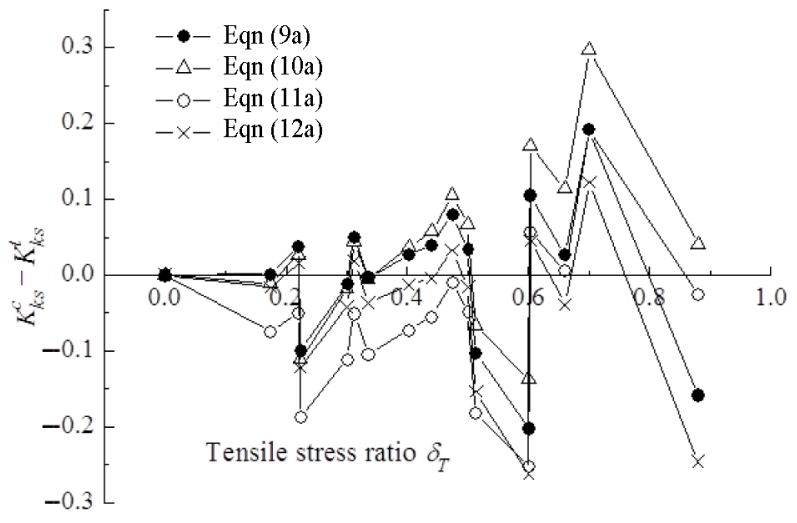

Fig. 3. Deviation between computed results and experimental data under tensile stress

Eqn (12a) are all fluctuating around 0. The maximum deviations from Eqn (9a) to Eqn (12a) are respectively $-0.202,0.297,-0.251$ and -0.262 , and the mean values of deviations are respectively $0.001,0.036,-0.057$ and -0.042 . Therefore, the results of deviations suggest that Eqn (9a) is the most accurate, followed by Eqn (10a), while Eqn (11a) is the least accurate.

As shown in Figure 4, with the increase of the concrete compressive stress ratio, the deviations of Eqn (9b) to Eqn (12b) are all fluctuating around 0. The fluctuation of Eqn (9b) is the smallest, with the maximum deviation and the mean values of deviations of 0.180 and 0.015 , respectively. In contrast, the maximum deviations of Eqn (10b) to Eqn (12b) are respectively 0.316, 0.340 and 0.247 , and the mean values of deviations are respectively $-0.083,0.030$ and 0.046 . The results of deviations

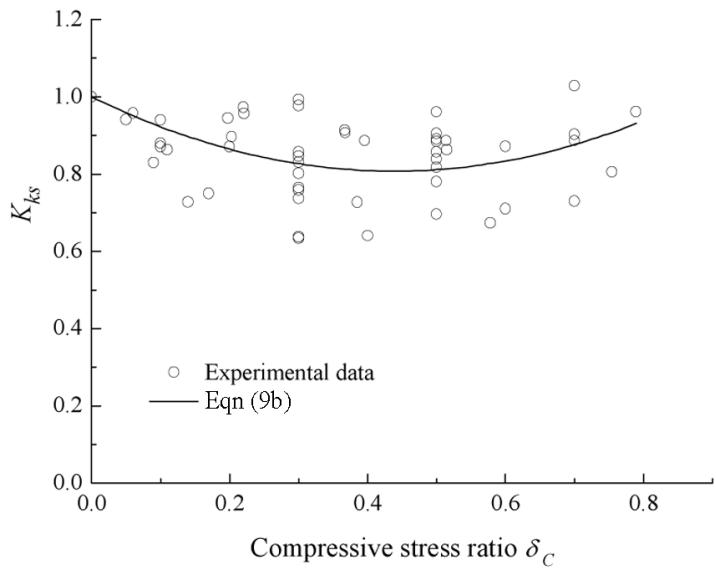

Fig. 2. Relationship between $K_{k s}$ and concrete compressive stress ratio $\delta_{C}$

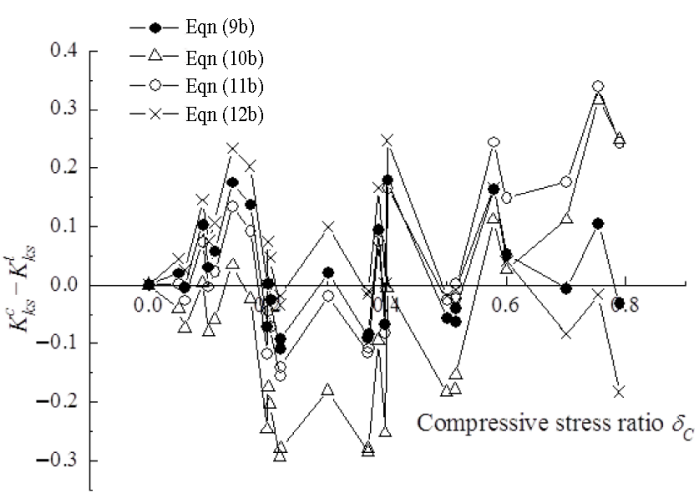

Fig. 4. Deviation between computed results and experimental data under compressive stress

suggest that Eqn (9b) is the most accurate, followed by Eqn (11b), while Eqn (10b) is the least accurate.

From the above, it can be seen that the proposed equations have the highest prediction accuracy in comparison with the typical existing equations.

\section{The modified chloride diffusion model}

Equation (6) can be rearranged to yield the general equation as given by Eqn (13), based on Eqn (7) to consider the effect of concrete stress state in term of the stress influence coefficient $K_{k s}$. When concrete is subjected to tensile stress or compressive stress, the value of $K_{k s}$ can be determined by Eqn (9a) or Eqn (9b), respectively. Eqn (13) can be taken as the governing equation of the modified chloride diffusion model:

$$
\begin{aligned}
& C_{x, t e}=C_{0}+k t_{e} \\
& \left\{\left[1+\frac{(x-\Delta x)^{2}(1-m)}{2 K_{k s} D_{r} t_{r}^{m}\left(\left[t_{e}+t_{a 0}\right]^{1-m}-t_{a 0}^{1-m}\right)}\right] \operatorname{erfc}\left[\frac{(x-\Delta x) \sqrt{1-m}}{2 \sqrt{K_{k s} D_{r} t_{r}^{m}\left(\left[t_{e}+t_{a 0}\right]^{1-m}-t_{a 0}^{1-m}\right)}}\right]-\frac{(x-\Delta x) \sqrt{1-m}}{\sqrt{\pi K_{k s} D_{r} t_{r}^{m}\left(\left[t_{e}+t_{a 0}\right]^{1-m}-t_{a 0}^{1-m}\right)}} \exp \left[\frac{-(x-\Delta x)^{2}(1-m)}{4 K_{k s} D_{r} t_{r}^{m}\left(\left[t_{e}+t_{a 0}\right]^{1-m}-t_{a 0}^{1-m}\right)}\right]\right\} .
\end{aligned}
$$


The modified chloride diffusion model can be used to predict the chloride concentration profiles that result from the chloride diffusion process under different concrete stress states in the first exposure period. It is noted that the proposed equations of $K_{k s}$ can also be used in the subsequent exposure periods with a constant surface chloride concentration and either a decreasing chloride diffusion coefficient or a constant chloride diffusion coefficient.

\section{Model validation}

In this section, the experimental data from He (2004), Wang (2012) and Wang et al. (2014) are used for validating the modified chloride diffusion model.

The specimens tested by $\mathrm{He}$ (2004) were concrete beams of size $100 \mathrm{~mm} \times 100 \mathrm{~mm} \times 400 \mathrm{~mm}$. Three factors were varied in the test, namely the water/cement ratio, load level and freeze-thaw cycle. During the loading test, three load levels corresponding to $0,0.3$ and 0.6 times the flexural strength of members were applied. At the same time, all concrete specimens were immersed in $3.5 \%$ sodium chloride solution. After 30, 70, 120 and 200 days of exposure to the sodium chloride solution, the chloride contents at different depths $(0-3,3-6,6-9,9-12,12-15$, and $15-20 \mathrm{~mm}$ ) from the exposed surface were determined.

The surface chloride concentrations from the specimens under zero load level at the convection zone depth ( $3 \mathrm{~mm}$ ) up to 200 days had a linear increase of surface chloride concentration, as given in Figure 5. The correlation coefficient $R^{2}$ is 0.984 , indicating a very good correlation between the experimental data and the regression equation. The best-fit curves for the experimental data at various ages can be obtained by varying the combinations of the input age factor and chloride diffusion coefficient. For unstressed specimens, the age factor is 0.32 and the chloride diffusion coefficient at 28 days is $7.12 \times 10^{-12} \mathrm{~m}^{2} / \mathrm{s}$. At the convection zone depth $(3 \mathrm{~mm})$, the experimental data are excluded. In Figure 6, the experimental data from specimens tested under 0.6 times

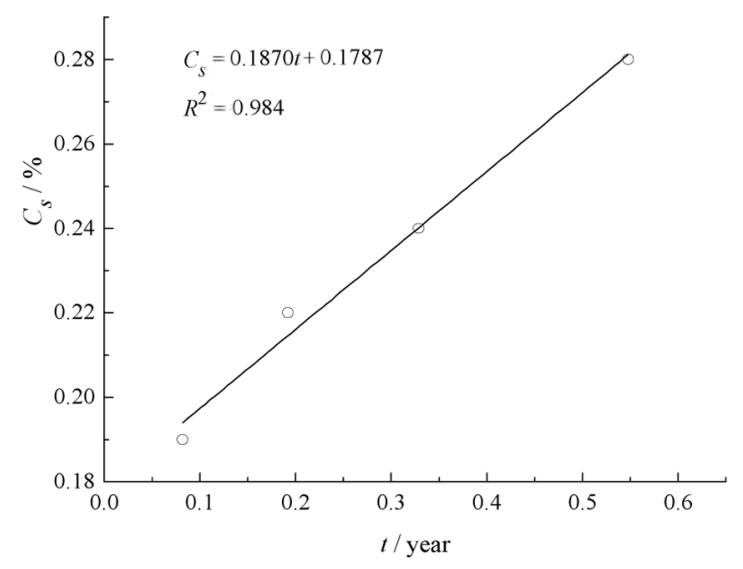

Fig. 5. Surface chloride concentration (data from He 2004) tensile strength are compared with the computed results from Eqn (13). As computed from Eqn (9a), when $\delta_{T}$ is $0.6, K_{k s}$ is equal to 1.27 . The $R^{2}$ value ranges from 0.904 to 0.964 . Overall, the correlation between the modified chloride diffusion model and the experimental data is good.

Wang et al. (2014) obtained the chloride profiles of specimens produced from ordinary Portland cement (P.O. 42.5) concrete at a water/cement ratio of 0.38 . The concrete specimens were placed in tidal zone and salt spray zone, respectively. Sodium chloride solution used in salt spray tests was made by dissolving sodium chloride in distilled water, and the mass fraction was $5 \%$. In salt spray tests, the concrete specimens were divided into four groups (five specimens per group) according to the required period of test $(35,70,120$ and 180 days). In each group, three load levels corresponding to $0,0.3$ and 0.5 times the flexural strength of member were applied. After 35, 70, 120 and 180 days of exposure to the chloride environment, the chloride contents in each concrete specimen at different depths $(0-5,5-10,10-15,15-20$, $20-25$, and $25-30 \mathrm{~mm}$ ) from the exposed surface were determined.

The experimentally obtained data of surface chloride concentrations of unstressed specimens at the convection zone depth $(5 \mathrm{~mm})$ up to 180 days $(0.493$ year) had an approximately linearly increasing trend, as shown in Figure 7 . The regression equation is presented in the figure and the $R^{2}$ value is 0.984 , indicating a very good correlation with the experimental result. The best-fit curves for the experimental data at various ages are obtained by varying the input age factor and chloride diffusion coefficient. For the unstressed concrete specimens, the values are evaluated as $m=0.21$ and $D_{28}=10.914 \times 10^{-12} \mathrm{~m}^{2} / \mathrm{s}$. At the convection zone depth $(5 \mathrm{~mm})$, the experimental data are excluded. The experimental data from concrete specimens tested at $\delta_{T}=0.5$ are compared with the computed results from Eqn (13), as depicted in Figure 8. From Eqn (9a), $K_{k s}$ is equal to 1.225 . The experimental data from concrete specimens tested at $\delta_{C}=0.3$ are com-

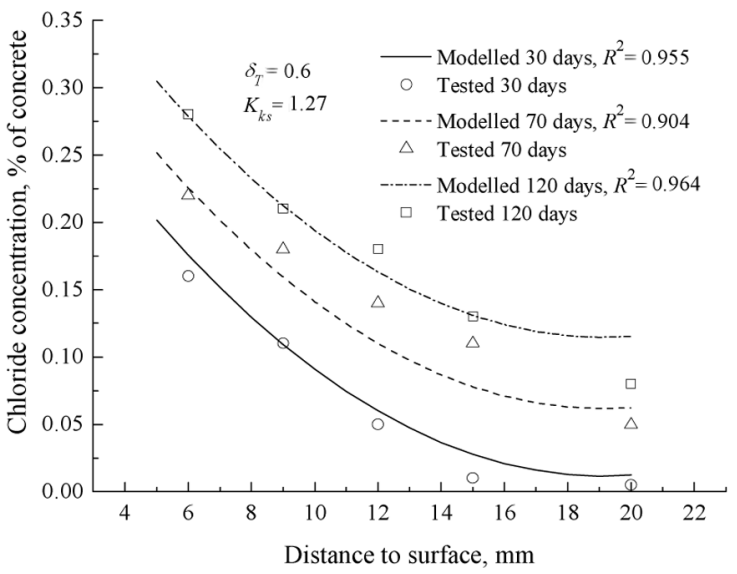

Fig. 6. Model validation (data from $\mathrm{He} 2004, \delta_{T}=0.6$, $\left.K_{k s}=1.27\right)$ 


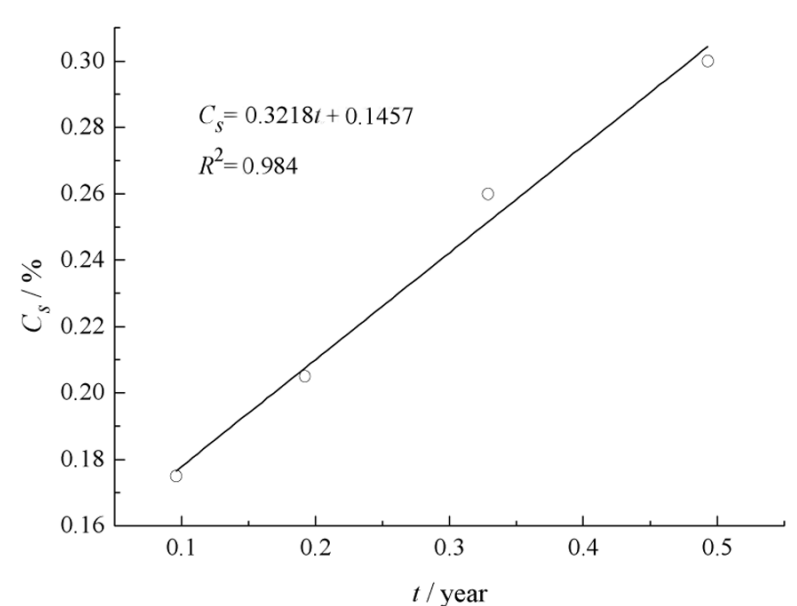

Fig. 7. Surface chloride concentration (data from Wang et al. 2014)

pared with the computed results from Eqn (13), as depicted in Figure 9. From Eqn (9b), $K_{k s}$ is equal to 0.826. It can be seen from Figures 8 and 9 that the computed results from Eqn (13) are very close to the experimental data. The $R^{2}$ value ranges from 0.907 to 0.997 , indicating very good correlation between the modified chloride diffusion model and the experimental data.

The concrete specimens tested by Wang (2012) were of size $100 \times 100 \times 400 \mathrm{~mm}$ and were divided into three categories, the first was compressive specimens with $\delta_{C}=0.1,0.2$ and 0.3 , the second was tensile specimens with $\delta_{T}=0.3,0.5$ and 0.7 , and the third was zero-stress specimens. Half of the total amounts of specimens were steam cured while the remaining half was cured under room temperature.

During testing, the concrete specimens were covered with sponge, except in the $50 \mathrm{~mm}$ distance from both ends of specimens. Chloride salt solution in 5\% concentration was sprinkled on the sponge three times per day. After 56, 112, 168 and 224 days of exposure to the

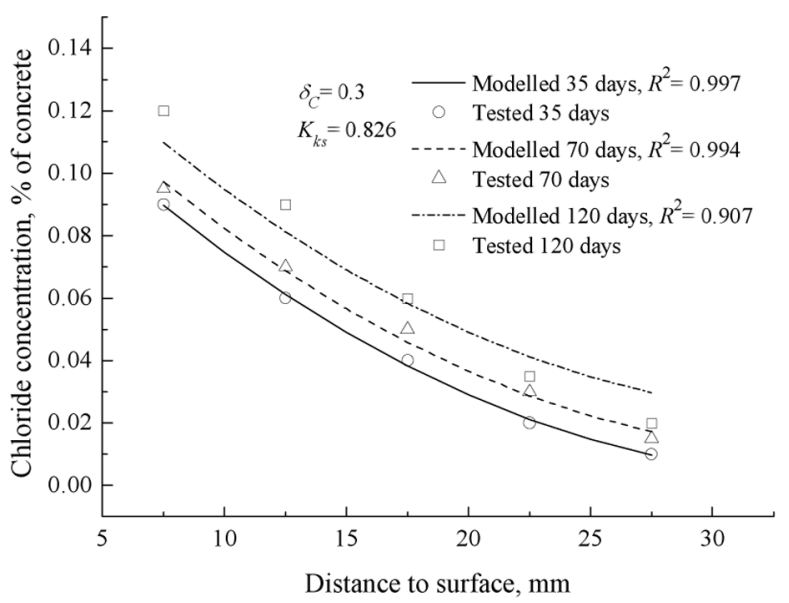

Fig. 9. Model validation (data from Wang et al. 2014, $\left.\delta_{C}=0.3, K_{k s}=0.826\right)$

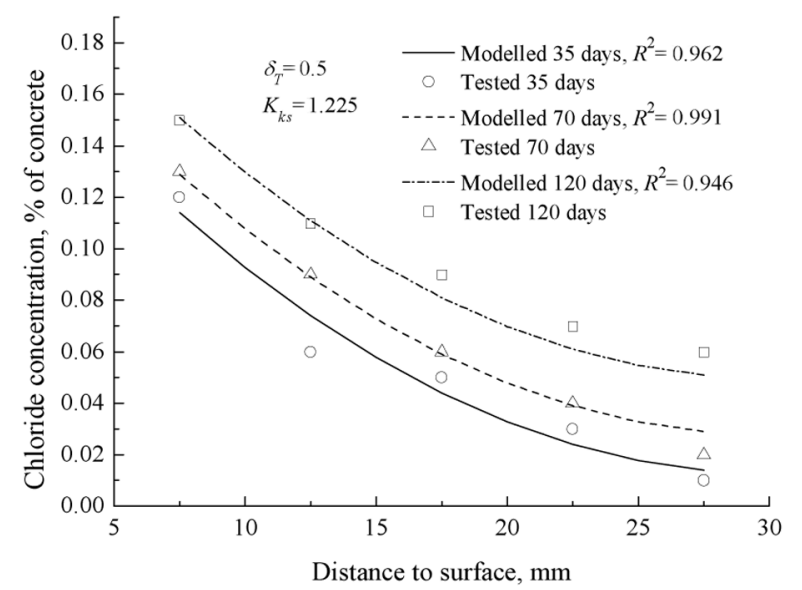

Fig. 8. Model validation (data from Wang et al. 2014, $\left.\delta_{T}=0.5, K_{k s}=1.225\right)$

chloride environment, the chloride contents at different depths $(0-5,5-15,15-25,25-35,35-45$, and $45-55 \mathrm{~mm})$ from the exposed surface were determined. The surface chloride concentrations from zero-stress specimens at the convection zone depth $(5 \mathrm{~mm})$ up to 224 days demonstrated an approximately linearly increasing trend, as shown in Figure 10. The $R^{2}$ value is 0.992 , indicating a very good correlation between the experimental result and the regression equation. The best-fit curves for the experimental data at various ages are obtained by varying the combinations of the input age factor and chloride diffusion coefficient. For the zero-stress specimens, the respective values are $m=0.25$ and $D_{28}=5.32 \times 10^{-12} \mathrm{~m}^{2} / \mathrm{s}$. At the convection zone depth $(5 \mathrm{~mm})$, the experimental data are excluded. The experimental data from concrete specimens tested at $\delta_{T}=0.5$ are compared with the computed results from Eqn (13), as presented in Figure 11. From Eqn (9a), $K_{k s}$ is equal to 1.225 . The experimental data from concrete specimens tested at $\delta_{C}=0.2$ are compared with the computed results from Eqn (13), as pre-

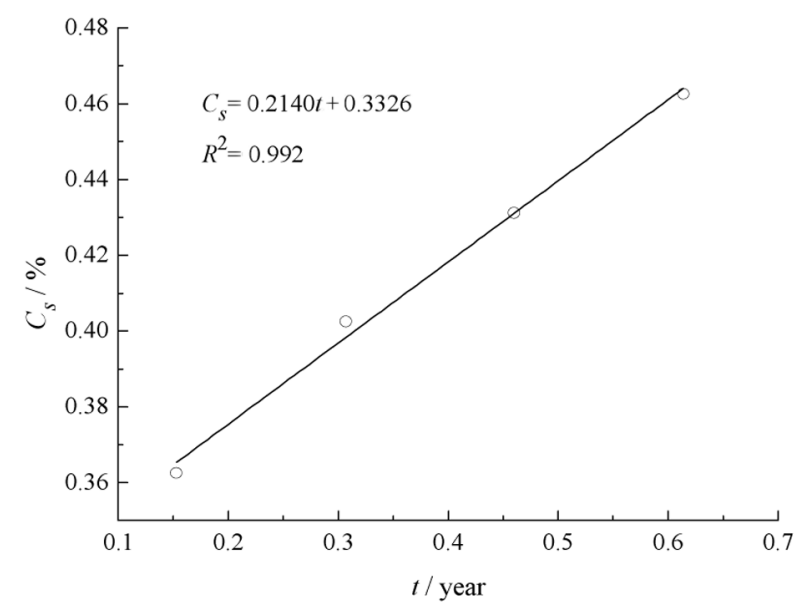

Fig. 10. Surface chloride concentration (data from Wang 2012) 


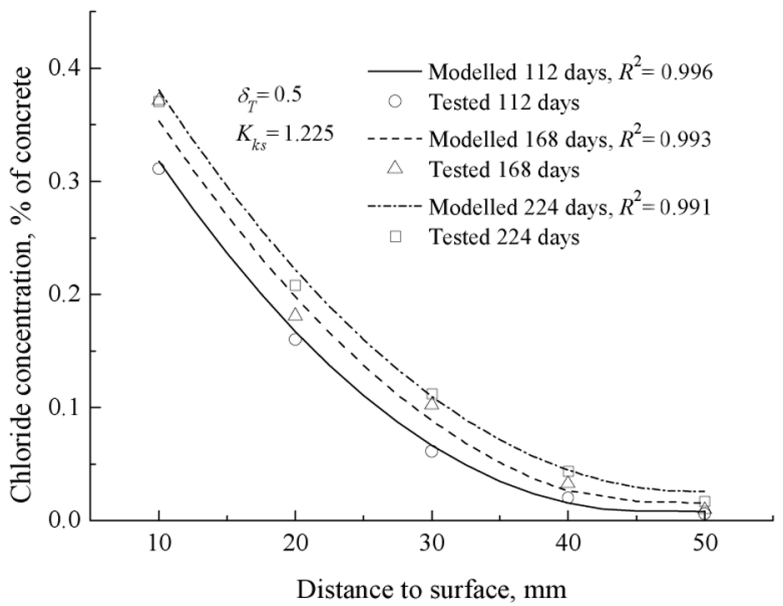

Fig. 11. Model validation (data from Wang 2012, $\delta_{T}=0.5$, $\left.K_{k s}=1.225\right)$

sented in Figure 12. From Eqn (9b), $K_{k s}$ is equal to 0.864. In Figures 11 and 12, the $R^{2}$ value ranges from 0.985 to 0.997 . The correlation between the modified chloride diffusion model and the experimental data is considered to be very good.

Overall, the results of the above validation show that the modified chloride diffusion model is accurate for predicting the chloride concentration profiles that result from the chloride diffusion process under different concrete stress states in the first exposure period. More data from experimental testing and field measurements for validating the new model are desirable.

\section{Conclusions}

In this paper, the influence of concrete stress states on chloride diffusion has been investigated with reference to collected experimental data in the literature. A modified chloride diffusion model has been proposed. From the analysis performed in this study, the following conclusions can be drawn:

1. The research has indicated that the stress influence coefficient has approximately linear relationship with the concrete tensile stress ratio, whereas the relationship between the stress influence coefficient and concrete compressive stress ratio is approximately a quadratic function. The stress influence coefficient increases with increasing concrete tensile stress ratio, while it first decreases and then increases with increasing concrete compressive stress ratio. By means of regression analysis, equations of stress influence coefficient have been established.

2 . To evaluate the accuracy of the proposed equations in this paper, they have been statistically compared with another three typical existing groups of equations in terms of the deviation. It is found that the proposed equations give the most accurate estimation of stress influence coefficient in comparison with the existing equations. Hence, the equations from the present research can be adopted to improve the valuation of chloride diffusion

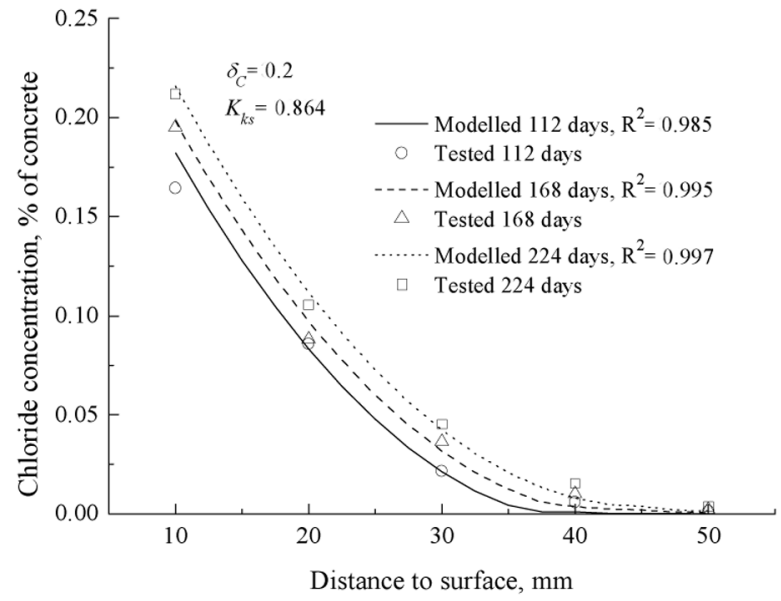

Fig. 12. Model validation (data from Wang 2012, $\delta_{C}=0.2$, $\left.K_{k s}=0.864\right)$

coefficient, and a modified chloride diffusion model has been put forward.

3. Three groups of experimental data have been used to validate the modified chloride diffusion model, and the results have shown that the modified chloride diffusion model is reasonable and has high prediction accuracy. Therefore, the modified chloride diffusion model can be used to predict the chloride diffusion process under different concrete stress states in the first exposure period. Nevertheless, the authors opine that the modified chloride diffusion model should be confirmed with more data obtained from experiment and field measurements. Moreover, further research regarding the possible influence of factors such as concrete mix design and environmental conditions on the stress influence coefficient is recommended.

\section{Acknowledgements}

The authors would like to gratefully acknowledge the financial support from Shanxi Provincial Transport Department of China (Grant No. 14 -16K), Ningbo Science and Technology Bureau of China (Grant No. 2015C110020), Open Research Project of Key Laboratory of Transportation for Old Bridge Inspection and Strengthening (Beijing), and Marie Skłodowska-Curie Actions of the European Commission (Project No. 751461) in carrying out this research.

\section{Disclosure statement}

The authors declare that they do not have any competing financial, professional, or personal interests from other parties.

\section{References}

Ababneh, A.; Benboudjema, F.; Xi, Y. 2003. Chloride penetration in nonsaturated concrete, Journal of Materials in Civil Engineering 15(2): 183-191. https://doi.org/10.1061/ (ASCE)0899-1561(2003)15:2(183) 
ACI Committee 365. 2000. Service-life prediction (ACI 365.1R00). American Concrete Institute, Michigan, USA. 44 p.

Álava, H. E.; Tsangouri, E.; Belie, N. D.; Schutter, G. D. 2016. Chloride interaction with concretes subjected to a permanent splitting tensile stress level of $65 \%$, Construction and Building Materials 127: 527-538. https://doi.org/10.1016/j.conbuildmat.2016.10.009

Costa, A.; Appleton, J. 1999. Chloride penetration into concrete in marine environment - Part I: Main parameters affecting chloride penetration, Materials and Structures 32(4): 252-259. https://doi.org/10.1007/BF02479594

Crank, J. 1975. The mathematics of diffusion. $2^{\text {nd }}$ ed. Clarendon Press, Oxford, UK. 424 p.

Ehlen, M. A.; Kojundic, A. N. 2014. Life- $365^{\mathrm{TM}}$ v2.2, Concrete International 36(5): 41-44.

Ehlen, M. A.; Thomas, M. D. A.; Bentz, E. C. 2009. Life-365 service life prediction model version 2.0, Concrete International 31(5): 41-46.

Fib Bulletin 34. 2006. Model code for service life design. Lausanne, Switzerland.

Fu, C. Q.; Ye, H. L.; Jin, X. Y.; Yan, D. M.; Jin, N. G.; Peng, Z. X. 2016. Chloride penetration into concrete damaged by uniaxial tensile fatigue loading, Construction and Building Materials 125: 714-723. https://doi.org/10.1016/j.conbuildmat.2016.08.096

Gowripalan, N.; Sirivivatnanon, V.; Lim, C. C. 2000. Chloride diffusivity of concrete cracked in flexure, Cement and Concrete Research 30(5): 725-730. https://doi.org/10.1016/S0008-8846(00)00216-7

He, S. Q. 2004. Experimental study on durability performance of reinforced concrete members under chloride environment: Dissertation. China: Dalian University of Technology. Available from Internet:

http://d.g.wanfangdata.com.cn/Thesis_Y687329.aspx

Huang, S. H. 2007. Study on durability of prestressed concrete structures against chloride erosion: Dissertation. China: Central South University. Available from Internet: http://d.g.wanfangdata.com.cn/Thesis Y1116824.aspx

Jin, W. L.; Yuan, Y. S.; Wei, J.; Wang, H. L. 2011. Theory and design on the durability of concrete structures. Science Press, Beijing, China.

Jin, L.; Zhang, R. B.; Du, X. L.; Li, Y. 2015. Multi-scale analytical theory of the diffusivity of concrete subjected to mechanical stress, Construction and Building Materials 95: 171-185. https://doi.org/10.1016/j.conbuildmat.2015.07.123

Kato, E.; Kato, Y.; Uomoto, T. 2005. Development of simulation model of chloride ion transportation in cracked concrete, Journal of Advanced Concrete Technology 3(3): 85-94. https://doi.org/10.3151/jact.3.85

Kim, D. H.; Shimura, K.; Horiguchi, T. 2010. Effect of tensile loading on chloride penetration of concrete mixed with granulated blast furnace slag, Journal of Advanced Concrete Technology 8(1): 27-34.

https://doi.org/10.3151/jact.8.27

Li, G.; Hu, F.; Wu, Y. 2011. Chloride ion penetration in stressed concrete, Journal of Materials in Civil Engineering 23(8): 1145-1153. https://doi.org/10.1061/(ASCE)MT.19435533.0000281

Li, H. M.; Wu, J.; Song, Y. J.; Wang, Z. 2014. Effect of external loads on chloride diffusion coefficient of concrete with fly ash and blast furnace slag, Journal of Materials in Civil Engineering 26(9): 309-313. https://doi.org/10.1061/(ASCE)MT.1943-5533.0000941

Life-365 ${ }^{\mathrm{TM}}$ Consortium $\square .2012$. Life-365 service life prediction model: and computer program for predicting the service life and life-cycle cost of reinforced concrete exposed to chlorides. Version 2.1.
Mustafa, M. A.; Yusof, K. M. 1994. Atmospheric chloride penetration into concrete in semitropical marine environment, Cement and Concrete Research 24(4): 661-670. https://doi.org/10.1016/0008-8846(94)90190-2

Meira, G. R.; Andrade, C.; Alonso, C.; Borba Jr., J. C.; Padiha Jr., M. 2010. Durability of concrete structures in marine atmosphere zones - The use of chloride deposition rate on the wet candle as an environmental indicator, Cement and Concrete Composites 32(6): 427-435. https://doi.org/10.1016/j.cemconcomp.2010.03.002

Rahman, M. K.; Al-Kutti, W. A.; Shazali, M. A.; Baluch, M. H. 2012. Simulation of chloride migration in compressioninduced damage in concrete, Journal of Materials in Civil Engineering 24(7): 789-796. https://doi.org/10.1061/(ASCE)MT.1943-5533.0000458

Sun, J. C.; Yao, Y.; Wang, L.; Wu, H. 2011. Chloride penetration of concrete under stress states, Low Temperature Architecture Technology 33(3): 1-3 (in Chinese).

Shui, J. F. 2005. Research on durability of reinforced concrete bridges in tide affected zone: Dissertation. China: Dalian University of Technology. Available from Internet: http://d.g.wanfangdata.com.cn/Thesis_Y825276.aspx

Stanish, K.; Thomas, M. 2003. The use of bulk diffusion tests to establish time-dependent concrete chloride diffusion coefficients, Cement and Concrete Research 33(1): 55-62. https://doi.org/10.1016/S0008-8846(02)00925-0

Shin, C. B.; Kim, E. K. 2002. Modeling of chloride ion ingress in coastal concrete, Cement and Concrete Research 32(5): 757-762. https://doi.org/10.1016/S0008-8846(01)00756-6

Tang, L.; Gulikers, J. 2007. On the mathematics of time-dependent apparent chloride diffusion coefficient in concrete, Cement and Concrete Research 37(4): 589-595. https://doi.org/10.1016/j.cemconres.2007.01.006

Wang, M. 2012. Carbonization and chlorine ion erosion test and theoretical analysis of steamed prestressed concrete: Dissertation. China: Central South University. Available from Internet: http://d.g.wanfangdata.com.cn/Thesis_Y2197234.aspx

Wang, H. L.; Lu, C. H.; Jin, W. L.; Bai, Y. 2011. Effect of external loads on chloride transport in concrete, Journal of Materials in Civil Engineering 23(7): 1043-1049. https://doi.org/10.1061/(ASCE)MT.1943-5533.0000265

Wang, Y. Z.; Lin, C.; Cui, Y. Q. 2014. Experiments of chloride ingression in loaded concrete members under the marine environment, Journal of Materials in Civil Engineering 26(6), 04014012.

https://doi.org/10.1061/(ASCE)MT.1943-5533.0000960

Wang, H. L.; Dai, J. G.; Sun, X. Y.; Zhang, X. L. 2016. Timedependent and stress-dependent chloride diffusivity of concrete subjected to sustained compressive loading, Journal of Materials in Civil Engineering 28(8), 04016059. https://doi.org/10.1061/(ASCE)MT.1943-5533.0001578

$\mathrm{Xu}$, J.; Li, F. M. 2017. A meso-scale model for analyzing the chloride diffusion of concrete subjected to external stress, Construction and Building Materials 130: 11-21. https://doi.org/10.1016/j.conbuildmat.2016.11.054

Zhang, D. F. 2001. Study on the durability of modern prestressed concrete structures: Dissertation. China: Southeast University. Available from Internet:

http://d.g.wanfangdata.com.cn/Thesis_Y489814.aspx

Zhang, T. W.; Gjørv, O. E. 1996. Diffusion behavior of chloride ions in concrete, Cement and Concrete Research 26(6): 907-917. https://doi.org/10.1016/0008-8846(96)00069-5

Zhang, H. R.; Zhao, Y. X. 2016. Performance of recycled concrete beams under sustained loads coupled with chloride ion $\left(\mathrm{Cl}^{-}\right)$ingress, Construction and Building Materials 128: $96-107$. https://doi.org/10.1016/j.conbuildmat.2016.10.028 
Zhou, S. 2014. Modeling chloride diffusion in concrete with linear increase of surface chloride, ACI Materials Journal 111(5): 483-490. https://doi.org/10.14359/51687160

Zhou, S. 2016. Analytical model for square root increase of surface chloride concentration and decrease of chloride diffusivity, Journal of Materials in Civil Engineering 28(4), 04015181.

https://doi.org/10.1061/(ASCE)MT.1943-5533.0001483
Zhou, Y.; Gencturk, B.; Willam, K.; Attar, A. 2015. Carbonation- induced and chloride - induced corrosion in reinforced concrete structures, Journal of Materials in Civil Engineering 27(9), 04014245. https://doi.org/10.1061/(ASCE)MT.1943-5533.0001209

Jian WANG. PhD student at the School of Civil Engineering, Beijing Jiaotong University, Beijing, China. Research interests: concrete structure durability, bridge maintenance and reinforcement.

Pui-Lam NG. Researcher at the Faculty of Civil Engineering, Vilnius Gediminas Technical University, Vilnius, Lithuania. He received his Bachelor and $\mathrm{PhD}$ degrees in civil engineering from the University of Hong Kong. He is a chartered civil engineer, and is recipient of Sir Edward Youde Memorial Fellowship (2005-2006), The HKIE Outstanding Paper Award for Young Engineers/ Researchers (2012), Certificate of Merit, The HKIE Innovation Awards for Young Members (2013 and 2017) by the Hong Kong Institution of Engineers, and Marie Skłodowska-Curie Actions Fellowship by the European Commission (2017-2019). Research interests: sustainable concrete materials and structures.

Weishan WANG. Senior structural engineer at the Highway Research Institute of Xi'an, Xi'an, China. Research interests: asphalt material, high-strength concrete material.

Jinsheng DU. Professor at the School of Civil Engineering, Beijing Jiaotong University, Beijing, China. He received his PhD in structural engineering in 2001 from Tsinghua University. Before he joined Beijing Jiaotong University, he worked in the University of Hong Kong as research associate (2002-2004). He is also a committee member of the China Civil Engineering Society. Research interests: externally and internally unbonded prestressed concrete structures, application of FRP materials in bridge engineering, monitoring and evaluation of bridge structures.

Jianyong SONG. PhD, Professor, Research Institute of Highway Ministry of Transport, Beijing, China. Research interests: bridge structure calculation theory, composite structure bridge, bridge detection, reinforcement and evaluation, bridge software development. 